\title{
Applying Feminist Poststructuralism as a Framework for Exploring Infant Feeding Interactions in the Neonatal Intensive Care Unit
}

\author{
Jacqueline van Wijlen', Megan Aston² \\ ${ }^{1}$ Rankin School of Nursing, St. Francis Xavier University, \\ ${ }^{2}$ Dalhousie University School of Nursing
}

Cite as CJCNC 2019 1(1), pp. 59-72

\begin{abstract}
Childbearing/rearing families in Canada face a variety of conflicting discourses related to infant feeding, entrenched in a complex web of gendered, social, institutional and political discourses. For parents of preterm and/or critically ill infants, this area remains largely under-explored through a feminist lens. We offer a critical examination of the applicability of feminist poststructuralism (FPS) as a theory to explore infant feeding interactions in the neonatal intensive care unit (NICU). Scholarly literature from diverse perspectives, including nursing, healthcare, gender studies, and social sciences is critiqued and the use of FPS as a guiding framework for nursing research and praxis is discussed. We discuss FPS and the relevance of various discourses to explore the phenomenon of infant feeding interactions in the NICU. Ultimately, we propose that FPS does offer a relevant lens through which to critically examine infant feeding interactions and bring voice to the complex processes embedded in the NICU.
\end{abstract}

Key Words: Feminist poststructuralism, nursing practice, infant feeding, breastfeeding, chestfeeding, neonatal intensive care unit.

\section{Author's Note}

It is important to acknowledge from the outset that the majority of current discourses around infant feeding involves the use of heteronormative terminology, such as 'breast milk' and/or 'breastfeeding' as well as 'mothers' in reference to the primary feeding/childbearing parents. At times, terminology such as 'human milk' or 'lactating parent' are used, although we personally find these terms to be somewhat reductionistic and disembodying in nature. In an effort to accurately reflect the work of the original authors cited in this manuscript while also acknowledging and respecting the experiences and identities of diverse childbearing families, we have chosen to bracket (chest) in relation to breastfeeding/breast milk throughout this work. We have also opted to use the terms 'primary feeding parent' and/or 'childbearing parent' in lieu of 'mother' whenever possible/appropriate.

Corresponding Author Jacqueline E. van Wijlen, Assistant Professor. C274 Camden Hall, Rankin School of Nursing, St. Francis Xavier University 2340 Notre Dame Avenue, PO Box 5000 Antigonish, NS Canada B2G 2W5S Email: jvanwijl@stfx.ca 


\section{INTRODUCTION}

Care provided to childbearing and childrearing families in our Canadian health care system is predominantly oriented through a mechanised medical model wherein the influence of patriarchal hegemony is evident. Consequently, the current climate of care is one that is largely focused on quantifiable outcomes and productivity, measured against Western standards, norms and ideals (Dykes, 2005; van Wijlen, 2019). As a result, the experience of providing and receiving care, particularly amongst marginalised populations, is largely decontextualised. We seek verifiable numbers, trends and success rates yet often fail to address or acknowledge the various contexts in which these are occurring. While paternalistic hegemony impacts all corners of health care (Cody, 2003; Aranda, 2018), it is acutely evident when exploring existing discourses relative to infant feeding. Infant feeding and the interactions inherent in the care, support and education surrounding its processes are embedded in complex social, political and cultural discourses (Smith, Hausman \& Labbok, 2012; Benoit, Goldberg \& Campbell-Yeo, 2016).

Research located in both qualitative and quantitative realms across diverse disciplines has sought to explore various facets related to infant feeding phenomena, including breast(chest) milk, formula feeding and everything in between. Feminist advocates have paid particular attention to infant feeding practices and their impact not only on women's health, but also the role that infant feeding-related decisions play in the lives of childbearing parents more broadly (Carter, 1995; Palmer, 2009; Taylor \& Wallace, 2012; Benoit, Goldberg \& Campbell-Yeo, 2016). Much of the critical dialogue focuses on patriarchal structures and narratives that underpin parenthood, exploring issues related to power as well as the personal, the political, and the ethical dimensions of health and wellbeing for women and childbearing persons.

At the forefront of the dominant health/medical infant feeding discourse, highly influential national and international health bodies, including the World Health Organization (WHO, 2001), the United Nations' Children's Fund (UNICEF, 2015) and the Canadian Paediatric Society (CPS, 2013) highlight breast(chest) milk as the optimal form of nutrition for all infants and advocate for exclusive breast(chest)feeding during the first six months of life and up to two years and beyond with the addition of complementary foods. As global leaders in health policy and health promotion, these organisations play a pivotal role in informing this discourse as they perpetuate certain values and beliefs relative to infant feeding. They cite a plethora of research that privileges breast(chest) milk and breast(chest)feeding as ideal for optimal health and wellbeing, not only for the child and primary feeding parent but also for the greater social sphere in which the feeding dyad is situated (Feldman-Winter, 2013; CPS, 2014). Through these narratives, much of the emphasis remains focused on the reduceable elements and nutrient properties of human milk as optimal in supporting physical health of infants and children, such as: growth and development, a healthy digestive system, improved immunity and reduced rates of diabetes (Meier, Engstrom, Patel, Jegier \& Burns, 2010; Infant Feeding Working Group, 2015; van Esterik \& O’Connor, 2017). This health/medical discourse, while valid and scientifically sound, has perpetuated scientific values related to breast(chest)feeding that does not easily incorporate the more relational aspects of the feeding process.

Historically, the culture around infant feeding showed a notable shift during the $20^{\text {th }}$ century when commercial infant formulas began being marketed by the 'childrearing experts' of the era (e.g. physicians) as the ideal form of nutrition for infants (Stevens, Patrick \& Pickler, 2009). This shift towards medicalisation of infant feeding began in the 1930s followed by an ongoing dichotomy and tension between breast(chest)milk and formula that has lasted for decades. Many authors in the 1980s wrote about the social construction of breast(chest)feeding (Aston, 1990; Haug, 1987; Rich, 1986) with Oakley (1986) clearly naming the impact of social and institutional influences, stating that "[t]he most obvious characteristic of society's attitudes to breastfeeding is that a society keeps changing its mind" (p. 87). For example, many feminist writers identified that physicians had great control over the postpartum period, bringing a biomedical perspective that women legitimised (Oakley, 1986). Subsequently, bottle feeding became the dominant way to feed one's newborn, particularly among the middle and upper classes. Those who were considered to be of a lower socio-economic status continued to breast(chest)feed as they could not afford to bottle feed and thus breast(chest)feeding was considered to be 'less than' (Palmer, 1988). As the commercialisation of infant formula took off, a notable decline in breast(chest)feeding global rates occurred (Stevens, Patrick \& Pickler, 2009). Feminist scholars, such as Palmer (2009), suggest that bottle feeding was presented to women during this era as a form of liberation, when in fact this was largely motivated by 
men and influential popular culture narratives as a way of discouraging breast(chest)feeding in order to maintain breasts as sexual objects.

While the 1970s saw a changing of the tides and the rise of breast(chest)feeding promotion efforts by key advocacy groups in the United States and abroad, it has taken several decades to shift the discourse to one that positively affirms breast(chest)feeding (Stevens, Patrick \& Pickler, 2009). This global shift included a strong reaction against the promotion of formula, particularly in developing countries where formula led to the death of many infants. The Nestle corporation is considered responsible by many for much of the devastating effects caused by formula feeding (Palmer, 1988). As described by Dalzell, Rogerson and Martindale (2010), the early 1990s also saw yet another key turning point in global-led initiatives to promote, protect and maintain breast(chest)feeding. An example of this is the Baby-Friendly Hospital Initiative (BFHI), a joint venture launched in 1991 led by the WHO and UNICEF (WHO \& UNICEF, 2018). Nevertheless, the dominant promotional narratives around breast(chest)feeding continue to be largely constructed by the scientific/medical discourses of nutrition and bonding that often silence other infant feeding practices.

As a key dimension of health, much of the work in and around infant feeding involves nurses, both in clinical and research capacities. Given the evidence supporting the benefits of skilled intervention and support on breast(chest)feeding outcomes (Dieterich, Felice, O'Sullivan \& Rasmussen, 2013; Patel \& Patel, 2016), training and educating nursing professionals in lactation support and promotion has been a considerable focus in recent decades in an attempt to shift infant feeding trends. The aforementioned BFHI framework is again an example of this in that hospitals and other health facilities are encouraged to become designated sites where breast(chest)feeding is promoted and formula use is discouraged, although still available if needed (WHO \& UNICEF, 2018).

Nurses and other health providers who care for critically acute infants in the neonatal intensive care unit (NICU) are particularly interested and engaged in complex feeding-related processes and outcomes. As the name implies, the NICU is a highly medicalised environment wherein care is provided to premature (born $\leq 37$ weeks' gestation) and/or critically ill infants and their families by a collaborative team of health professionals. The uncertainty of outcomes and the fragility of life in this area requires complex interventions, careful monitoring, and frequent separation of the infant from their families (Obeidat,
Bond \& Callister, 2009). Within this space, nutrition and infant feeding-related practices are of primary concern for nurses and other care providers and the processes involved in providing nourishment to preterm and critically ill infants presents unique challenges for all involved (Cricco-Lizza, 2016; Hurst, Engebreston \& Mahoney, 2013).

As a result, the feeding-related interactions between nurses and families in this setting are invariably complex and thus raise the following questions: How do families and nurses experience different feeding discourses while in the NICU? How do families and nurses challenge, accept and make meaning out of different feeding discourses? And, How do they experience relations of power? Examining available literature related to infant feeding in the NICU highlights that a paucity of feminist exploration and discussion exists, particularly from a poststructuralist perspective. This presents a unique opportunity to examine and deconstruct the different meanings of discourses related to infant feeding, explore the relevance and applicability of feminist poststructuralist theory to this area of care as well as the potential for feminist poststructuralism to guide future nursing research and practice.

Through the background and discussion that follows, we will begin by providing a concise overview of feminism and feminist poststructuralism followed by a succinct summary of relevant infant feeding issues and related interactions in the NICU environment. This will provide important context when considering how infant feeding in the NICU may differ from infant feeding outside of the NICU space. Following this, we will discuss the relevance and applicability of feminist poststructuralism as a framework for guiding nursing practice and research in the neonatal intensive care setting, specifically as it relates to infant feeding interactions between nurses and primary feeding parents. While an extensive overview of the her(his)torical narratives that have shaped contemporary infant feeding practices and discourses is beyond the scope of this paper, we endeavour to foreground the critical areas with pivotal points in this complex her(his)story as they relate to the topics explored in this discussion.

\section{AIM}

The aim of this discursive paper is to critically examine the applicability of feminist poststructuralism (FPS) as a theoretical framework for exploring infant feeding interactions experienced by primary feeding parents in the neonatal intensive care unit (NICU). 
FPS will provide a lens to understand a variety of infant feeding discourses that may compete, conflict or overlap. As a paucity of literature on FPS in the context of the NICU environment related to infant feeding and other phenomena currently exists, this paper seeks to set the groundwork for future critical research in order to begin to address this identified gap.

\section{DESIGN \& METHODS}

Integration of relevant infant feeding discourses from a variety of disciplines, including nursing and gender studies is drawn on to argue for the application of a feminist poststructural framework in exploring infant feeding interactions between nurses and primary feeding parents in the neonatal intensive care unit. The applicability and relevance of FPS as a framework for nursing research and practice is discussed as we critique literature retrieved from diverse nursing and allied health databases (i.e., CINAHL, PubMed, Google Scholar), women's and gender studies literature, and the social sciences. Reflexivity, recognition of interlocking identities and acknowledgment of positions of power and privilege are important feminist practice within research. As such, we as authors acknowledge that our identities and privileges as nursing scholars are also integral to shaping and informing the discussion that follows.

\section{BACKGROUND}

\section{Feminism: A Focused Overview}

Feminist scholars and activists recognise the imperative role of gender in shaping the experiences of all individuals, as well as the pervasive influence of sexuality, power and politics in our daily lives (Aranda, 2006; Weedon, 1997). Feminist theorist bell hooks offers a simple, open-ended definition of feminism, describing it as "[...] a movement to end sexism, sexist exploitation, and oppression" (hooks, 2015 , p. 1). She emphasises that understanding sexism and the impact of sexist thinking at the individual as well as systemic levels is essential to understanding feminism and creating effective change (hooks, 2015). In this vein, the patriarchal structures of our society are considered a starting point within feminism, referring to relations of power that subordinate the interests of women (and arguably, other marginalised groups), to the interests of men (Weedon, 1997). These relations can take many forms, including the social organisation of reproduction and the sexual division of labour (Weedon, 1997).
For decades, feminists have worked at dismantling patriarchal structures and influences through theory, research and action in order to seek emancipation. Much of the work of feminists is political; contemporary feminism itself draws on its roots as a political movement, heavily influenced by Women's Liberation in the 1960s (Weedon, 1997; Greaves, 2018). The slogan 'the personal is political', recited frequently in the context of feminist scholarship and activism, draws attention to the everyday, lived reality and social status of women that is both informed and shaped by politics (hooks, 2000; Aston, 2016). It draws us to reflect on the daily experiences of oppression, exploitation, and discrimination faced by women within the confines of a patriarchal society.

While a key tenet of feminism involves examining gender inequality and inequities, conducting health research through a feminist lens also aims to challenge dominant narratives and understandings of women's experiences, particularly related to health and reproduction (Aranda, 2018). In doing so, it effectively gives voice to women's accounts, advocating for their rights, and produces a diverse body of knowledge (Aranda, 2018). Through feminist health research, we can effectively explore and deconstruct gendered power dynamics innate in our highly paternalistic, Western model of health care delivery. Aranda (2018) discusses how feminists have challenged essentialist, reductionistic views on nature and biology as fixed (or 'destined'), emphasising the importance and relevance of socio-cultural and historical contexts and the impacts of gender and gender inequality in health. Feminist research not only brings visibility to women's experiences but also has the power to address the circumstances which perpetuate their inequitable social positions (Edwards, 2005), offering a way forward in addressing gender inequities in health and health services.

A significant body of work applying feminist theory and feminist frameworks in exploring the multi-facets of parenting, in particular motherhood, exists. Different streams of feminism, ranging from liberal to radical, have explored various dimensions of this construct; focusing on the impact of gender inequality, power, politics, historical and socio-cultural on reproduction, pregnancy, infant feeding and more (Snitow, 1992; McCarter-Spaulding, 2008; Neyer \& Bernardi, 2011). Aranda (2018) refers to motherhood as a "[...] complex set of bodily practices" (p. 147), wherein childbearing bodies, as well as decisions related to these bodies, are frequently considered public and thus subject to discussion, debate and outside opinion. Consider for a moment the stream of 
pervasive discourses faced by childbearing people; the pressure to not only conform with paternalistic societal ideals but also the need to negotiate and position oneself in relation to the opinions and expectations of others (Aranda, 2018).

In one relevant example from a feminist perspective, Carroll (2014) discusses the concept of reproductive labour (or care work), which refers to the contributions of women's domestic, childbearing and childrearing work. This labour is often largely invisible, yet it contributes significantly to the health and wellbeing as well as the financial economy and productivity of our society. The act of breast(chest)feeding or pumping breast(chest) milk to provide to one's own infant(s), or the children of others (i.e., wet nursing or for milk donation), would be considered a form of reproductive labour (Carroll, 2014).

Feminism is not without its challenges. Feminists themselves have identified that a central issue in feminist debate has been the lack of consensus around a unifying definition of what feminism is, as well as what the future of feminism looks like (hooks, 2010). In turn, many misunderstand feminism completely, interpreting it as an anti-male movement or view it simply as a movement to make women and men social equals (hooks, 2010; 2015). In addition, much discussion and criticism has arisen around the privileging of gender in feminist theory over other aspects of identity such as race, class and sexual orientation (DiQuinzio, 1993). This is particularly true of feminists making universal claims around 'women's experiences/situations/voices', which are particularly problematic when rooted from the perspectives of white, heterosexual, middle-to-uppermiddle class women and effectively exclude the experiences of women who do not fall into these categories (DiQunizio, 1993).

Despite these challenges and critiques, there is much space within feminism and feminist theory for growth, interpretation and application. The ongoing theoretical development of Black feminism, postcolonial feminism, and the integration of intersectionality and queer theory within feminist frameworks (to name a few) are all examples of ways in which feminism is diversifying within research and praxis.

\section{Feminist Poststructuralism}

As its name implies, feminist poststructuralism (FPS) is philosophically underpinned by the tenets of both feminism and poststructuralism, largely influenced by the writings of philosophers and scholars such as
Michel Foucault, Chris Weedon, Joan Scott, Judith Butler and Julianne Cheek. It has been referred to as a "passionately interested form of inquiry" (Aranda, 2006, p.135), one that seeks to challenge the status quo and address imbalances of power imposed by patriarchy. As both a philosophy and methodology for conducting nursing research, FPS can be used in a variety of settings and offers a way of both understanding and addressing personal, social and institutional practices (Aston, 2016). While its feminist underpinnings offer a lens on the role of gender (as well as sexuality, class, race and ability), the poststructural dimension offers a perspective on knowledge and relations of power. It critically applies concepts of language, meaning, beliefs, values, practices, subjectivity and agency in order to deconstruct existing power relations, identify areas in need of change and the strategies in which to do so (Weedon, 1997).

Given the converging philosophies of poststructuralism and feminism that inform FPS, it can be challenging to reconcile all philosophical dimensions into a cohesive framework for guiding research and praxis. Recognising this, Aston (2016), a feminist poststructuralist nursing researcher, has identified eight overarching principles of FPS, which are summarised briefly below:

1. Power as Relational: Power goes beyond the interactions between two individuals; it is the meaning appointed to the interaction that defines it - it is not static. This highlights the importance of understanding not only the intent of the individuals, but also the social and institutional contexts in which the interactions take place.

2. Binary Opposites: Refers to subject positions shaped as part of social and institutional constructions that pigeon-hole individuals into stereotypical positions influenced by power. These are problematic, yet as identified by Foucault (1982), they are an important starting point for critical analysis. Examples can include the power of men over women, health care providers over patients, and governments over populations.

3. Regulated Communications: Addressing the interactions that are constructed by, and embedded in, society and in institutions. It includes the concept of self-monitoring (Foucault, 1982), wherein individuals monitor their own practices as well as the practices of others; it is connected to social norms, values, beliefs and practices. 
4. Feminist Theory: Going beyond gender and a focus on the oppression of women specifically, feminist philosophical and theoretical concepts within FPS are relevant in multiple contexts. As Aston (2016) explains, feminist analyses allow us to understand how all individuals (not just women) either internalise or resist economic, cultural, and social power relations.

5. Discourse Analysis: Discourse analysis is a cornerstone within FPS. Understanding the relevance and importance of discursive fields (Weedon, 1987, 1997) in order to be able to understand how individuals experience power as well as to be able to examine how discourses interact and compete, is key. Discursive fields impact how individuals act and interpret their circumstances, depending on what discourses are made available to them. Analysis of discourse allows us to examine the influence of power on the experiences of individuals and offer in-depth understanding.

6. Language and Meaning: Critical attention to language is essential and is the site where meanings are produced. Language exists within historically-specific discourses, and as such, meanings are not fixed and can change depending on the discursive context or setting.

7. Beliefs, Values and Practices: Using these concepts to guide our analyses (and practice) ensures that we have a clear understanding of another's experience and that we are not merely interpreting them based on our own assumptions.

8. Subjectivity and Agency: Subjectivity relates to being conscious of one's self and how individuals are positioned while also being reflexive during the process of working, with, through and against the influence of social discourses. How an individual chooses to act in a given situation (e.g., complying or resisting), relates to their agency.

In sum, feminist poststructuralism offers a synergistic approach to exploring and understanding relations of power through analysis of various forms of discourse, drawing on tenets of both feminism and poststructuralism. It is a dynamic methodology that allows us to critically and reflexively explore a wide range of phenomena, in health care and beyond (Aranda, 2006). In the proceeding section, we will discuss how FPS offers a promising framework for exploring infant feeding-related interactions between nurses and families within the neonatal intensive care unit.

\section{A Concise Overview of Relevant Infant Feeding Discourses}

A current dominant discourse around infant feeding in the Western world is one that is largely oriented through a medicalised/scientific, heteronormative lens that advocates for breast(chest) milk as the ideal form of infant nutrition as it is believed to be nutritionally superior to bottle feeding, fostering better physical health outcomes for mother and infant. As noted earlier, this discourse has changed over many decades and has been influenced by ongoing research supporting that breast(chest)milk as the nutritionally superior option. After the dramatic shift to bottle feeding in the earlier $20^{\text {th }}$ century, it has taken several decades to reverse this narrative, led largely by promotional campaigns and health advocacy at many levels. Current breast(chest)feeding rates in the Canada appear to average $89 \%$ initially postpartum with a rapid decline to less than $40 \%$ at the six-months postpartum mark (Gionet, 2013; Statistics Canada, 2019). Realising that even though many parents do in fact have knowledge about the nutritional and physiological benefits of breast(chest) milk, these facts alone are not enough to keep them breast(chest)feeding. Therefore, highlighting the more relational aspects of breast(chest)feeding is also key, such as bonding and skin-to-skin care. It is important to recognise that there are a variety of infant feeding discourses laden with different beliefs, values and practices. As such, we need to pay attention to how parents are experiencing these different meanings and how they affect their decisions related to infant feeding.

Recent literature from nursing and the social sciences have highlighted the importance of the emotional aspect of the breast(chest) feeding experience, creating opportunities for relational moments (Dykes \& Flacking, 2010; Van Esterik \& O'Connor, 2017). The positioning of different discourses in relation to a dominant medicalised/scientific infant feeding discourse through relations of power can cause a mixture of feelings and reactions depending on how one chooses to participate in or challenge each discourse. A focus on the physiological processes of lactation and other associated components and outcomes as collected through quantitative investigations continues to dominate the focus on infant feeding (Victora et al., 2016; Perella et al., 2012; Schanler, 2011; Johnson, Williamson, Lyttle \& Leeming, 2009). While qualitative research has also been utilised to explore the experiences of primary feeding parents, it often lacks critical exploration of the broader socio-cultural and institutional contexts in which these individuals, and their experiences, are situated (Johnson et al., 2009). 
Primary feeding parents, the vast majority of whom are described as women and/or mothers, are situated in complex social, political, historical and cultural contexts wherein they face several conflicting messages around infant feeding (van Wijlen, 2019). Decisions related to infant feeding are largely subject to the weighty gaze of health care professionals, family, friends and strangers; pressures to conform to societal norms and ideals are pervasive in the context of infant feeding. Narratives such as 'breast is best' as well as reference to breast(chest) milk as 'liquid gold' dominate public and institutional discourses that perpetuate the belief that breast(chest) milk is best for the baby; however, much has also been written about the harm that this belief has on those who cannot or choose not to breast(chest)feed (Thomson, EbischBurton \& Flacking, 2015; Alianmoghaddam, Phibbs \& Benn, 2017; Aston, 2002, 2006, 2008). Murphy (1999, 2000) identifies that regardless of whether infants are bottle/formula or breast(chest)fed, mothers (or primary feeding parents) face what she calls a 'moral minefield' wherein breast(chest) milk is presented as the 'right choice' associated with being a 'good mother' and bottle/formula feeding is the 'wrong choice' tied to being a 'bad' mother. This is based on different beliefs and values, and ultimately, different discourses that create meaning regarding infant feeding practices.

Unsurprisingly, a common theme of guilt and shame also dominates the literature; authors such as Taylor and Wallace (2012), Thomson, Ebisch-Burton and Flacking (2015), as well as Benoit, Goldberg and Campbell Yeo (2016) have explored the prevalence and impact of shame and guilt related to both breast(chest)feeding and formula feeding on childbearing families. The use of emotional coercion and guilt tactics to influence infant feeding-related decisions is also discussed (Taylor \& Wallace, 2012). Utilising these methods both directly and indirectly raise serious ethical and moral concerns. As several feminist scholars have identified, the decision to breast(chest)feed largely goes beyond choice - it is a complex process entrenched in one's social and economic location, intricately linked with gender and positions of privilege and power (Brown, 2017; Smith, 2018; Smith, Hausman \& Labbok, 2012; Palmer, 2009). Creating safe spaces to identify and discuss different breast(chest)feeding discourses if often difficult. We have only highlighted some of the main discourses that have stood out in the literature, however, we believe there are other discourses that have not yet been named - discourses that may surface as we continue to explore and examine experiences of infant feeding. For example, sexual health discourses regarding women's breasts may also influence parental and nurses' experiences of infant feeding depending on personal and social beliefs regarding breasts. Discourses of gender identity, chestfeeding, and/or trauma and abuse are other experiences that need to be examined in relation to infant feeding. Infant feeding is complex and requires careful examination of many different facets of the situation. It is important to understand how personal choices are connected to social and institutional discourses and feminist poststructuralism could provide a lens to understand the complex relations of power that we will discuss below.

\section{Infant Feeding in the NICU}

The acuity and highly technical realm of the neonatal intensive care unit creates a complex environment for both care providers and families. Admission of a preterm and/or critically ill infant to the NICU is typically an unexpected event for parents (Shattnawi, 2015), posing unique stressors and altering the birthing experience from what is often anticipated in the days and months leading up to a 'typical' birth. Existing neonatal literature has established that the experiences of parents of preterm and/or critically ill infants differs from those of healthy, term infants and that NICU admission elicits feelings of heightened anxiety, emotional and psychological distress (Boykova, 2016; Bicking \& Moore, 2012).

Not unlike infant feeding discourses related to term/healthy infants, it is evident in much of the NICU literature that breast(chest) milk is considered the 'optimal' form of nutrition in comparison to formula. As argued in a recent critical discussion piece, the act of breast(chest)feeding and/or producing breast(chest) milk is given new meaning within the NICU setting (van Wijlen, 2019). In this context, it goes beyond a life-sustaining form of nourishment, frequently presented by NICU care providers as a life-saving intervention based on its immunological and nutritive benefits (van Wijlen, 2019). This inevitably constructs the scientific/medical discourse in a different way and imposes high moral stakes related to infant feedingrelated decisions for parents of infants in the NICU without necessarily considering the contexts and complexities of the parental 'choice' being made.

Infant feeding takes on a wide range of forms in the NICU. Due to medical acuity, many infants admitted to neonatal intensive services require several interventions to sustain life and receive essential nutrition. Use of assistive and/or interventional aids to facilitate, replace or supplement feeding, such as total parenteral nutrition (TPN), nipple shields and gavage 
tubes, are not uncommon. If the infant cannot latch onto the breast but is receiving breast(chest) milk through a tube or other device, this would require the lactating parent, or in some cases an adoptive parent to use a breast(chest) pump to extract breastmilk (Meier et al., 2010). Qualitative research on breast(chest) milk expression has revealed that this process elicits a continuum of emotions for mothers (primary feeding parents), ranging from feelings of detachment/separation to a sense of empowerment at being able to actively participate in their infant's care (Hurst, Engebreston \& Mahoney, 2013; Boucher et al., 2011; Johnson et al., 2009). This is an example of how women may react differently to the same discourse of infant feeding in the NICU. Interestingly, mothers (primary feeding parents) who participated in a study by Hurst, Engebreston and Mahoney (2013) also identified feelings of objectification as the breast(chest) milk they produced and pumped was examined and scrutinised by staff, negatively impacting their breast(chest)feeding experience. This could be seen as a type of surveillance as presented by Foucault. Relations of power are negotiated differently by each parent depending on how they feel about their breast(chest)milk being monitored. The use of donor human milk is another feeding avenue that requires parents to think about feeding their infant in yet another way. While it is still breast(chest) milk, it may elicit a variety of emotional issues for parents that can be both positive or negative depending on their own personal beliefs and values as well as those perpetuated by the health care system in which they are situated.

\section{DISCUSSION}

We believe that a feminist poststructural framework offers an ideal lens through which to examine infant feeding in the NICU as it acknowledges the gendered, historical and political contexts in which decisions and interactions related to infant feeding occur and allows space for critical discussion and exploration (Paynter \& Goldberg, 2018; Smith, Hausman \& Labbok, 2012; Johnson et al., 2009; McCarter-Spaulding, 2008). Feminist poststructural theory offers a powerful framework for reaching beyond the surface of issues related to oppression and social justice, allowing for explicit exploration with the ultimate goal of emancipatory action. While many feminists and streams of feminism take different (and often polarizing) stances on infant feeding in relation to gender and oppression (McCarter-Spaulding, 2008; Taylor \& Wallace, 2012; Smith, Hausman \& Labbok, 2012), they also offer critical points of discussion and reflection to challenge the status quo and address patriarchal hegemony. Poststructuralism also offers a way to deconstruct experiences and understand experiences from the vantage point of different discourses through relations of power.

Focusing more specifically on infant feeding in the context of parents of premature and critically ill infants, it is evident that there is a void in feminist literature related to infant feeding interactions in neonatal intensive care units. As of the writing of this paper, we were able to locate only a handful of graduate theses (e.g., Marcotte, 2017; Inglis, 2010; Blackburn, 2009) and peer-reviewed journal articles (e.g., Deeney, Lohan, Spence \& Parkes, 2012; Layne, 1996) that explicitly acknowledge using feminist lenses and/or frameworks to guide their work related to the NICU population/environment. Most significantly, no articles specifically identifying feminist poststructuralism as a framework or methodology for guiding research or practice in the neonatal intensive care space could be identified.

\section{Relevance of FPS to Clinical Nursing Practice \& Scholarship}

With societal obsession over the governance, surveillance and control of bodies, particularly as it relates to reproduction and childrearing (Foucault, 1975/1979; Aranda, 2018), the application of FPS frameworks in both nursing practice and research, is highly relevant. Women and childbearing parents are impacted to varying degrees by intersections of gender, class, ethnicity and sexuality within a complexly layered social and cultural narrative. As Aston and colleagues (2012) explain, utilising a feminist poststructural form of inquiry within nursing research and practice has the capacity to bring to the forefront the social, political and institutional beliefs that influence the interactions between nurses and the clients with whom they work. It allows the researcher to disrupt what is 'known' and question the authority/power of broader metanarratives in favour of multivocality and unearthing new possibilities (Aranda, 2006). FPS also challenges oppressive and dominant patriarchal structures, which are evident within the NICU context, and Western medical culture more broadly (van Wijlen, 2019).

It is important to reiterate that while the feminist underpinnings of FPS may imply a stance that focuses largely on women and women's issues, it is considered applicable in a wide range of research contexts given its methodological flexibility and overarching focus on relations of power (Aston, 2016). The applicability and relevance of FPS as a guiding framework for 
nursing practice and research has been effectively demonstrated in a number of health care settings and across a diverse spectrum of populations, including (but not limited to): sexual health, postpartum home visits, bereavement follow-up, eHealth and obesity (Richardson, Goldberg, Aston \& Campbell-Yeo, 2018; Cassidy, Goldberg \& Aston, 2016; Aston et al., 2015; MacConnell, Aston, Randel \& Zwaagstra, 2012; Aston, Price, Kirk \& Penney, 2012). In the context of infant feeding, authors such as Johnson et al. (2009) and Alianmoghaddam, Phibbs \& Benn (2017) have applied FPS and other poststructural forms of analysis to explore this construct. As mentioned above, no studies to date could be identified that applied FPS to infant feeding interactions located specifically within the neonatal intensive care environment.

As we have demonstrated, infant feeding interactions in the NICU are largely influenced by a dominant medical discourse surrounding these processes. Given that these interactions are entrenched in a complicated web of gendered, social, institutional and political influences that construct the dominant narrative, it is evident that a critical framework for exploration and analysis is necessary. As presented earlier in the paper, other non-medicalised infant feeding discourses exist. With the use of FPS, we can begin to explore and examine how mothers, parents and health care professionals experience each of these discourses through beliefs, values and meaning about different infant feeding practices. Their experiences can also be understood through relations of power that will show how certain discourses become dominant and other discourses subordinate. It will also show how discourses compete, overlap and compliment. Knowing that dominant discourses exist is a call to action for an in-depth, critical exploration of the relations of power and how they are positioned in relation to the phenomenon of infant feeding interactions between nurses and families in the NICU. As an approach that offers a needed critical deconstruction of the "[...] gendered, racial and sexuality-based inequities [related to] opportunities, resources, status and power" (Smith, 2018, p. 221) surrounding infant feeding, feminist poststructuralism is a seemingly natural fit to answer this call.

With power relations being a focal concept of FPS, we are drawn within this framework to examine how interactions between individuals (i.e., nurses and parents) are influenced by their surrounding social and institutional contexts (Aston, 2016). This has the capacity to offer NICU nurses, parents and researchers a theoretical framework that allows them to further examine and reflect on their own infant feeding interactions and discourses. In addition, gaining this understanding of power relations provides a starting point through which the 'privileges of knowledge' (Aston, 2016) that exist within the nurse-parent dynamic and its surrounding context can be examined.

Feminist poststructuralism also challenges binaries, going beyond the male/female binary to also include other potentially oppressive binaries (Davies \& Gannon, 2010), such as health care providers (i.e., nurses) and care recipients (i.e., infants and families in the NICU). As a methodology, FPS makes these binaries "visible, analyzable, and revisable" (Davies \& Gannon, 2010, p. 312) and further illuminates how power relations are constructed and maintained. In addition, a focus on the beliefs, values and practices of NICU parents relative to infant feeding interactions is key, for nursing researchers and clinicians alike. FPS brings these principles to the forefront, calling us to be reflexive and pay greater attention to the experiences of those we are caring for and/or constructing knowledge with, as opposed to our own personal values and beliefs.

While the feminist perspective is particularly relevant given the gendered underpinnings of nursing and motherhood in this setting, the role of feminist theory within FPS goes beyond gender and also brings forth a way of understanding the surrounding social, political, historical and institutional dimensions at play (Aston, 2016; Weedon, 1997). This allows space and opportunity for more inclusivity of multiple gender identities in this context as well as acknowledgment of the broader contextual factors that impact the lives and experiences of NICU families.

The application of FPS-guided discourse analysis (DA) provides nursing researchers and clinicians with an approach to critically analyse multiple forms of language and discourse related to feeding interactions in the NICU. It offers a method of uncovering how dominant ideologies are reproduced through discourse within their surrounding sociocultural and political contexts (Lupton, 1992). A critical analysis of multiple discursive mediums is possible in relation to infant feeding interactions in the NICU - e.g., verbal interactions between nurses and parents, relevant medical documentation, unit policies and feeding education materials - all of which may yield a richer, in-depth understanding of how infant feeding is negotiated within the NICU environment. 


\section{CONCLUSION}

Within the complexly-layered and inextricably gendered constructions of parenthood and infant feeding, the interconnected dynamics related to the broader themes of power and oppression contribute to both perpetuating existing discourse while also creating calls to action in shifting current narratives. Feminist poststructuralism offers a unique and relevant lens through which to critically examine infant feeding interactions and bring voice to the 'unseeable' and 'unsaid' complexities embedded within these processes in the neonatal intensive realm.

Nurses who work with infants, childbearing persons and families - in the NICU and beyond - are uniquely positioned to critically reflect on the language and actions used when engaging in feeding-related interactions. In doing so, there exists the possibility not only of challenging the status quo, but also identifying opportunities for necessary change and action. Ultimately, beginning to shift the discourse relative to infant feeding interactions in the highly-medicalised environment of the NICU is a necessary and important step towards reframing breast(chest)feeding, breast(chest) milk and formula feeding practices in this area. In light of the unique challenges and triumphs faced by NICU parents, this shift has the potential to offer a profound change in their infant feeding-related experiences.

\section{ETHICAL PERMISSIONS}

Given the theoretical nature of this discursive manuscript, ethical permissions were not sought nor required as no participants were involved.

\section{REFERENCES}

Alianmoghaddam, N., Phibbs, S. \& Benn, C. (2017). Resistance to breastfeeding: A Foulcauldian analysis of breastfeeding support form health professionals. Women and Birth, 30, e281-e291. doi: 10.1016/j.wombi.2017.05.005

Aranda, K. (2006). Postmodern feminist perspectives and nursing research: A passionately interested form of inquiry. Nursing Inquiry, 13(2), 135-143. doi: 10.1111/j.1440-1800.2006.00310.x

Aranda, K. (2018). Feminist theories \& concepts in healthcare: An introduction for qualitative research. London, UK: Macmillan Publishers Ltd.
Aston, M. (1990). Bonding sounds too much like glue: Pedagogical implications of the experiences of breastfeeding. Masters Thesis, Kingston, ON: Queen's University.

Aston, M. (2002). Learning to be a normal mother: Empowerment and pedagogy in postpartum classes. Public Health Nursing, 19(4), 284-293.

Aston, M., Meagher-Stewart, D., Sheppard-LeMoine, D., Vukic, A. \& Chircop, A. (2006). Family health nursing and empowering relations. Pediatric Nursing, 32(1), 61-67.

Aston, M. (2008). Public health nurses as social mediators: Using feminist poststructuralism to guide practice with new mothers. Nursing Inquiry, 15(4) 280-288. doi: 10.1111/j.14401800.2008.00408.x

Aston, M. (2016). Teaching feminist poststructuralism: Founding scholars still relevant today. Creative Education, 7(15), 2251-2267. doi: 10.4236/ce.2016.715220

Aston, M., Price, S., Etowa, J., Vukic, A., Young, L., Hart, C., MacLeod, E. \& Randel, P. (2015). The power of relationships: Exploring how public health nurses support mothers and families during postpartum home visits. Journal of Family Nursing, 21(1), 11-34. doi: $\underline{10.1177 / 1074840714561524}$

Aston, M., Price, S., Kirk, S.F.L. \& Penney, T. (2012). More than meets the eye. Feminist poststructuralism as a lens towards understanding obesity. Journal of Advanced Nursing, 68(5), 11871194. doi: 10.1111/j.1365-2648.2011.05866.x

Benoit, B., Goldberg, L. \& Campbell-Yeo, M. (2016). Infant feeding and maternal guilt: The application of a feminist phenomenological framework to guide clinician practices in breastfeeding promotion. Midwifery, 34, 58-65. doi: $\underline{10.1016 / j . m i d w .2015 .10 .011}$

Bicking, C. \& Moore, G.A. (2012). Maternal perinatal depression in the neonatal intensive care unit: The role of the neonatal nurse. Neonatal Network, 31(5), 295-304. doi: 10.1891/07300832.31.5.295

Boykova, M. (2016). Transition from hospital to home for parents of preterm infants: A literature review. Journal of Perinatal and Neonatal Nursing, 30(4), 327-348 doi: 10.1097/JPN.0000000000000211 
Blackburn, A.C. (2009). Stories, ethics and the interpretations of meaning: Bearing witness to mothers' stories of their neonatal intensive care experience. Doctoral Thesis, Retrieved from: https://aquila.usm.edu/cgi/viewcontent.cgi?article $=20$ $28 \&$ context $=$ dissertations

Boucher, C.A., Brazal, P. M., Graham-Certosini, C., Carnaghan-Sherrard, K. \& Feeley, N. (2011). Mother's breastfeeding experiences in the NICU. Neonatal Network, 30(1), 21-28. doi: 10.1891/0730$\underline{0832.30 .1 .21}$

Brown, A. (2017). Breastfeeding as a public health responsibility: A review of the evidence. Journal of Human Nutrition \& Dietetics, 30(6), 759-770. doi: $\underline{10.1111 / \mathrm{jhn} .12496}$

Canadian Paediatric Society. (2013). Nutrition for healthy term infants, birth to six months: An overview. Retrieved from: https://www.cps.ca/en/documents/position/nutritionhealthy-term-infants-overview

Canadian Paediatric Society. (2014). Nutrition for healthy term infants, six to 24 months: An overview. Pediatric Child Health, 19(10), 547-549.

Carroll, K. (2014). Body dirt or liquid gold? How the 'safety' of donated breastmilk is constructed for use in the neonatal intensive care unit. Social Studies of Science, 44(3), 466-485.

doi: $10.1177 / 0306312714521705$

Carter, P. (1995). Feminism, breasts and breastfeeding. New York, NY: Palgrave Macmillan.

Cassidy, C. Goldberg, L. \& Aston, M. (2016). The application of a feminist poststructural framework in nursing practice for addressing young women's sexual health. Journal of Clinical Nursing, 25, 2378-2386. doi: 10.1111/jocn.13354

Cody, W.K. (2003). Paternalism in nursing and healthcare: Central issues and their relation to theory. Nursing Science Quarterly, 16(4), 288-296. doi: $10.1177 / 0894318403257170$

Cricco-Lizza, R. (2016). Infant feeding beliefs and day-to-day feeding practices of NICU nurses. Journal of Pediatric Nursing, 31(2), e91-e98. doi: 10.1016/j.pedn.2015.10.012
Dalzell, J., Rogerson, E. \& Martindale, L. (2010). Breastfeeding: Contemporary issues in practice and policy. Oxon, UK: Radcliffe Publishing Ltd.

Davies, B. \& Gannon, S. (2010). Feminism/poststructuralism (Ch. 36). In B. Somekh \& C. Lewin's (eds.) Research Methods in the Social Sciences $\left(2^{\text {nd }}\right.$ ed.). Thousand Oaks, CA: SAGE Publications. pp. 312-319.

Deeney, K., Lohan, M., Spence, D., Parkes, J. (2012). Experiences of fathering a baby admitted to neonatal intensive care: A critical gender analysis. Social Science \& Medicine, 75(6), 1106-1113. doi: $\underline{10.1016 / \mathrm{j} . \text { socscimed.2012.04.018 }}$

Dieterich, C.M., Felice, J.P., O’Sullivan, E. \& Rasmussen, K.M. (2013). Breastfeeding and health outcomes for mother-infant dyad. Pediatric Clinics of North America, 60(1), 31-48. doi:

10.1016/j.pcl.2012.09.010

DiQuinzio, P. (1993). Exclusion and essentialism in feminist theory: The problem of mothering. Hypatia, $8(3), 1-20$.

Dykes, F. (2005). 'Supply' and 'demand':

Breastfeeding as labour. Social Science \& Medicine, 60(10), 2283-2293. doi:

10.1016/j.socscimed.2004.10.002

Dykes, F. \& Flacking, R. (2010). Encouraging breastfeeding: A relational perspective. Early Human Development, 86(11), 733-736. doi: 10.1016/j.earlhumdev.2010.08.004

Edwards, N.P. (2005). Birthing autonomy: Women's experiences of planning home births. New York, NY: Routledge.

Feldman-Winter, L. (2013). Evidence-based interventions to support breastfeeding. Pediatric Clinics of North America, 60(1), 169-187. doi: 10.1016/j.pcl.2012.09.007

Foucault, M. (1975/1979). Discipline and punish: The birth of the prison. New York, NY: Vintage Books.

Foucault, M. (1982). The subject and power. Critical Inquiry, 8(4), 777-795. 
Gionet, L. (2013). Breastfeeding trends in Canada (Statistics Canada Catalogue No. 82-624-X).

Retrieved from: https://www.statcan.gc.ca/pub/82624-x/2013001/article/11879-eng.htm

Greaves, L. (2018). Personal and political: Stories form the women's health movement 19602010. Toronto, ON: Second Story Press.

Haug, F. (1987). Female sexualization: A collective work of memory. Norfolk, UK: Thetford Press. hooks, b. (2000). Feminist theory: From margin to center $\left(2^{\text {nd }}\right.$ ed). Brooklyn, NY: South End Press.

hooks, b. (2015). Feminism is for everybody: Passionate politics. New York, NY: Routledge.

Hurst, N., Engebreston, J. \& Mahoney, J.S. (2013). Providing mothers' own milk in the context of the NICU: A paradoxical experience. Journal of Human Lactation, 29(3), 366-373.

doi: $10.1177 / 0890334413485640$

Infant Feeding Working Group. (2015). Nutrition for healthy term infants:Recommendations from birth to six months. Retrieved from: https://www.canada.ca/en/healthcanada/services/food-nutrition/healthy-eating/infantfeeding/nutrition-healthy-term-infantsrecommendations-birth-six-months.html\#a3

Inglis, D. (2010). A feminist phenomenological study of skin-to-skin contact with mothers and nurses in NICU. Masters' Thesis, Retrieved from ProQuest Dissertations \& Theses Global (UMI No. MR63637).

Jefferies, A.L. (2014). Going home: Facilitating discharge of the preterm infant (Canadian Pediatric Society position statement). Paediatrics \& Child's Health, 19(1), 31-36.

Johnson, S., Williamson, I., Lyttle, S. \& Leeming, D. (2009). Expressing yourself: A feminist analysis of talk around expressing breast milk. Social Science \& Medicine, 69(6), 900-907. doi: 10.1016/j.socscimed.2009.07.001

Layne, L. (1996). "How's the baby doing?"

Struggling with narratives of progress in a neonatal intensive care unit. Medical Anthropology Quarterly, 10(4), 624-656.

Lupton, D. (1992). Discourse analysis: A new methodology for understanding the ideologies of Health and illness. Australian Journal of Public Health, 16(2), 145-150.
MacConnell, G., Aston, M., Randel, P. \& Zwaagstra, N. (2012). Nurses' experiences providing bereavement follow-up: An exploratory study using feminist poststructuralism. Journal of Clinical Nursing, 22(7-8), 1094-1102. doi: 10.1111/j.13652702.2012.04272.x

Marcotte, M. (2017). Examining the climate for aboriginal mothers in neonatal intensive care units (NICUs): An exploratory qualitative study about views of health care professionals. Doctoral Thesis, Retrieved from:

https://unbc.arcabc.ca/islandora/object/unbc\%3A173 78/datastream/.../unbc_17378.pdf

Murphy, E. (1999). 'Breast is best': Infant feeding decisions and maternal deviance. Sociology of Health \& Illness, 21(2), 187-208.

Murphy, E. (2000). Risk, responsibility, and rhetoric in infant feeding. Journal of Contemporary Ethnography, 29(3), 291-325.

Lee, R. (2018). The ethics and politics of breastfeeding: Power, pleasure, poetics. Toronto, ON: University of Toronto Press.

McCarter-Spaulding, D. (2008). Is breastfeeding fair? Tensions in feminist perspectives on breastfeeding and the family. Journal of Human Lactation, 24(2), 206212. doi: $10.1177 / 0890334408316076$

Nathoo, T. \& Ostry, A. (2009). The one best way? Breastfeeding history, politics, and policy in Canada. Waterloo, ON: Wilfrid Laurier University Press.

Neyer, G. \& Bernardi, L. (2011). Feminist perspectives on motherhood and reproduction. Historical Social Research, 36(2), 162-176. doi: 10.12759/hsr.36.2011.2.162-176

Oakley, A. (1986). Telling the truth about Jerusalem. New York, NY: Basil Blackwell.

Obeidat, H.M., Bond, E.A. \& Callister, L.C. (2009). The parental experience of having an infant in the newborn intensive care unit. The Journal of Perinatal Education, 18(3), 23-29. doi:10.1624/105812409X461199

Palmer, G. (1988). The politics of breastfeeding. London, UK: Pandora Press.

Palmer, G. (2009). The politics of breastfeeding: 
When breasts are bad for business. ( $3^{\text {rd }}$ ed.). London, U.K.: Pinter \& Martin Ltd.

Patel, S. \& Patel, S. (2016). The effectiveness of lactation consultants and lactation counselors on breastfeeding outcomes. Journal of Human Lactation, 32(3), 530-541. doi: 10.1177/0890334415618668

Paynter, M. \& Goldberg, L. (2018). A critical review of human milk sharing using an intersectional feminist framework: Implications for practice. Midwifery, 66, 141-147. doi:10.1016/j.midw.2018.08.014

Perrella, S.L., Williams, J., Nathan, E.A., Fenwick, J., Hartmann, P.E., \& Geddes, D.T. (2012).

Influences on breastfeeding outcomes for healthy term and preterm/sick infants. Breastfeeding Medicine, 7(4), 255-261. doi:10.1089/bfm.2011.0118

Rich, A. (1986). Of woman born: Motherhood as experience and institution. New York, NY: W.W. Norton and Company.

Richardson, B., Goldberg, L., Aston, M. \& Campbell-Yeo, M. (2018). eHealth versus Equity: Using a feminist poststructural framework to explore the influence of perinatal eHealth resources on health equity. Journal of Clinical Nursing, 27, 4224-4233. doi: 10.1111/jocn.14592

Schanler, R.J. (2011). Outcomes of human milk-fed premature infants. Seminars in Perinatology, 35(1), 29-33. doi: 10.1053/j.semperi.2010.10.005

Shattnawi, K.K. (2015). Suspended liminality: Breastfeeding and becoming a mother in two NICUs. International Journal of Advanced Nursing Studies, 4(2), 75-84. doi: 10.14419/ijans.v4i2.4877

Smith, P.H., Hausman, B.L. \& Labbok, M. (2012). Beyond health, beyond choice: Breastfeeding constraints and realities. New Brunswick, NJ: Rutgers University Press.

Smith, P.H. (2018). Social justice at the core of breastfeeding protection, promotion and support: A conceptualization. Journal of Human Lactation, 34(2), 220-225. doi: 10.1177/0890334418758660

Snitow, A. (1992). Feminism and motherhood: An American reading. Feminist Review, 40, 32-51.

Statistics Canada. (2019). Exclusive breastfeeding, at least 6 months, by age group [Table 13-10-0096-22]. Retrieved from: https://www150.statcan.gc.ca/t1/tbl1/en/tv.action?pid $=1310009622$

Stevens, E.E., Patrick, T.E. \& Pickler, R. (2009). A history of infant feeding. The Journal of Perinatal Education, 18(2), 32-39 doi:10.1624/105812409X426314

Taylor, E.N. \& Wallace, L.E. (2012). For shame: Feminism, breastfeeding advocacy, and maternal guilt. Hypatia, 27(1), 76-98. doi:10.1111/j.15272001.2011.01238.x

Thomson, G., Ebisch-Burton, K. \& Flacking, R. (2015). Shame if you do - shame if you don't: Women's experiences of infant feeding. Maternal \& Child Nutrition, 11(1), 33-46. doi: $\underline{10.1111 / \mathrm{mcn} .12148}$

UNICEF. (2015). Breastfeeding. Retrieved from: https://www.unicef.org/nutrition/index_24824.html

van Esterik, P. \& O'Connor, R.A. (2017). The dance of nurture: Negotiating infant feeding. New York, NY: Berghahn Books.

van Wijlen, J.E. (2019). Breastfeeding woman or lactating object? A critical philosophical discussion on the influence of Cartesian dualism on breastfeeding in the neonatal intensive care unit. Journal of Clinical Nursing, 28(5-6), 1022-1031. doi: 10.1111/jocn.14686

Victora, C. G., Bahl, R., Barros, A.J.D., França, G.V.A., Horton, S., Krasevec, J., . . Rollins, N. C. (2016). Breastfeeding in the 21 st century: Epidemiology, mechanisms, and lifelong effect. The Lancet, 387(10017), 475-490. doi: 10.1016/S01406736(15)01024-7

Weedon, C. (1997). Feminist practice \& poststructuralist theory ( $2^{\text {nd }}$ ed.). Oxford, UK: Blackwell Publishing.

World Health Organization. (2001). The optimal duration of exclusive breastfeeding: Report of an expert consultation (WHO/NHD/01.09). Geneva, $\mathrm{CH}$ : Author. Retrieved from:

http://apps.who.int/iris/bitstream/10665/67219/1/WH O_NHD_01.09.pdf?ua=1

World Health Organization. (2014). Global nutrition targets 2025: Breastfeeding policy brief 
(WHO/NMH/NHD/14.7). Geneva, CH: Author.

Retrieved from:

http://apps.who.int/iris/bitstream/10665/149022/1/W

HO_NMH_NHD_14.7_eng.pdf?ua $=1$

World Health Organization and United Nations Children's Fund. (2018). Implementation guidance: Protecting, promoting, and supporting breastfeeding in facilities providing maternity and newborn services - the revised Baby-Friendly Hospital Initiative. Geneva, CH: Author. Retrieved from: https://apps.who.int/iris/bitstream/handle/10665/2729 $\underline{43 / 9789241513807-e n g . p d f ? u a=1}$ 